\title{
Esophageal lipoma presenting as a long tongue!!
}

\section{Krishnaveni Janarthanan • Shiran Shetty • A. Mohanakrishnan • Venkatakrishnan Leelakrishnan}

Published online: 17 August 2011

(C) Indian Society of Gastroenterology 2011

A 42-year-old man presented with history of non progressive dysphagia both for solids and liquids for the past 2 years. He used to bring out a fleshy mass from mouth during retching, followed by choking. Upper gastrointestinal endoscopy revealed a soft, long, smooth, bulging lesion in the upper esophagus, extending for a length of $20 \mathrm{~cm}$. Pillow-sign was positive. Patient coughed immediately after the procedure, and brought out a fleshy pink tubular mass with a blind end from the mouth (Fig. 1), which caused sudden choking. The mass was maneuvered back by the patient himself. Endoscopic ultrasound showed hyperchoic lesion arising from the third layer of esophageal wall suggestive of lipoma. His CT thorax showed submucosal elongated polypoidal lesion with feeding blood vessels, and luminal narrowing in the upper part of the esophagus (Fig. 2). Surgical excision of the

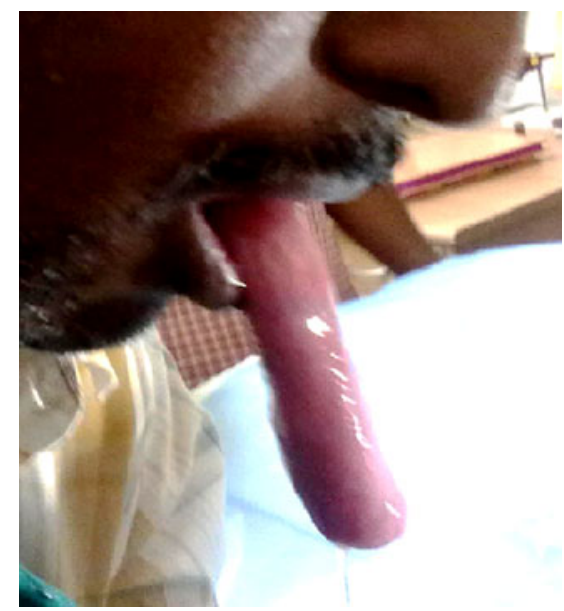

Fig. 1 Fleshy tongue like tubular mass protruding from mouth after endoscopy

K. Janarthanan $(\varangle) \cdot$ S. Shetty $\cdot$ A. Mohanakrishnan $\cdot$

V. Leelakrishnan

P S G Institute of Medical Sciences and Research,

Coimbatore 641 001, Tamil Nadu, India

e-mail: venijana@yahoo.co.in

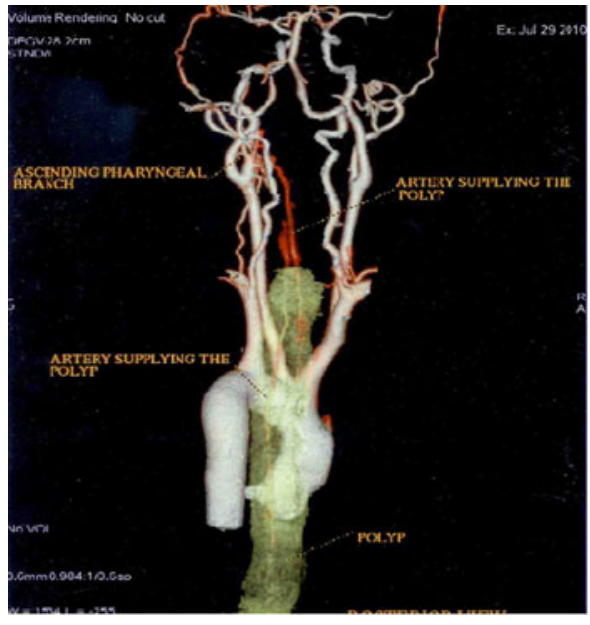

Fig. 2 CT thorax showing polypoidal lesion with feeding blood vessel

lipoma was done with endoscopic assistance. Histology revealed mature adipocytes suggestive of lipoma; there was no increased mitotic activity or lipoblasts.

Lipomas of the esophagus are usually asymptomatic. Since the lipomas are pedunculated, those in the cervical esophagus may regurgitate and cause sudden choking and death [1]. The diagnosis can be made by endoscopy, endoscopic ultrasound [2] or CT . Most esophageal lipomas are small, solitary and do not require any intervention. Symptomatic lesions can be managed by endoscopic removal or surgery [3].

\section{References}

1. Akiyama S, Kataoka M, Horisawa M, et al. Lipoma of the esophagus - report of a case and review of the literature. Jpn J Surg. 1990;20:458-62.

2. Murata Y, Yoshida M, Akimoto S, Suzuki S, Hanyu F. Evaluation of endoscopic ultrasonography for the diagnosis of submucosal tumors of the esophagus. Surg Endosc. 1988;12:51-8.

3. Hosokawa O, Shirasaki I, Sandou N. Endoscopic removal of esophageal lipoma. Gastroenterolog Endosc. 1985;27:738-43. 